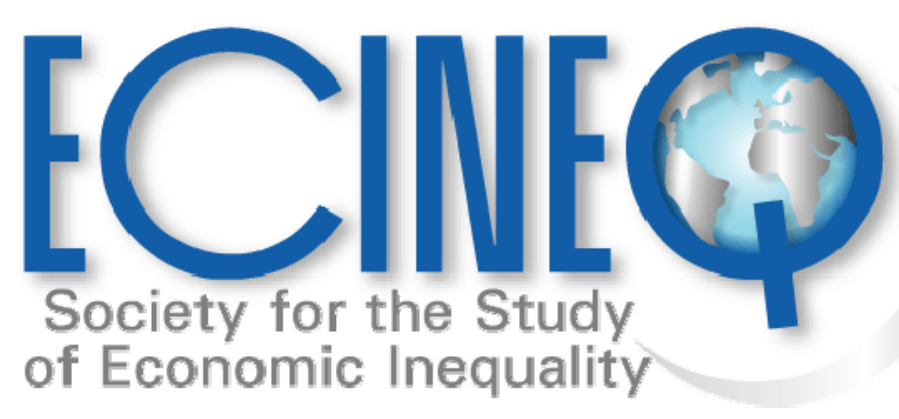

Working Paper Series

Higher education and equality of opportunity in Italy

Vito Peragine

Laura Serlenga 
ECINEC 2007-79

November 2007

www.ecineq.org

\title{
Higher education and equality of opportunity in Italy ${ }^{*}$
}

\author{
Vito Peraginet and Laura Serlenga \\ University of Bari
}

November 6, 2007

\begin{abstract}
This paper proposes a definition of equality of educational opportunities. Then, it develops a comprehensive model that allows to test for the existence of equality of opportunity in a given distribution and to rank distributions according to equality of opportunity. Finally, it provides an empirical analysis of equality of opportunity for higher education in Italy.
\end{abstract}

JEL Classification: D63, I2, C14

Keywords: Equality of Opportunity, Higher Education, Stochastic Dominance

\footnotetext{
* An earlier version of the paper was presented at seminars in Milan and Siena, at the II Meeting of the ECINEQ Society in Berlin, at the II Winter School on Inequality and Collective Welfare Theory in Canazei, at the XX SIEP Conference in Pavia, and at the EEEPE meeting in London. We would like to thank the participants at these conferences and seminars for their discussion of the paper. Moreover, we are particularly grateful to Valentino Dardanoni, Carlo Fiorio and Alain Trannoy for valuable comments and suggestions. The usual disclaimer applies † Department of Economics, University of Bari, Via C.Rosalba, 53, 70124 Bari, tel. +390805049051, E-mail: v.peragine@dse.uniba.it

¥ Address for correspondence: Department of Economics, University of Bari, Via C.Rosalba, 53, 70124 Bari, tel. +390805049043, e-mail: laura.serlenga@dse.uniba.it
} 


\section{Introduction}

Equality of opportunity (EOp) is a widely accepted principle of distributive justice in western liberal societies and it is the leading idea of most political platforms in several countries. The crucial role played by the educational system in determining the extent of equality of opportunity and intergenerational mobility in a society is also broadly recognized. It is, therefore, of prime policy interest to evaluate the effects of education policies from the point of view of equality of opportunity. However, in addition to data limitation and empirical constraints, such evaluation is by no means straightforward from a theoretical point of view.

It is sometimes thought that opportunity equalization, in the dimension of education, is implemented by the provision of equal educational resources to all young citizens; alternatively, by the provision of equality in the educational attainments of all individuals. At times, "equality of opportunities for education" is invoked as the "right" principle of justice in that particular sphere of social life.

What does this exactly means? Arrow et al. (2000) for instance argue that "even so basic a concept as equality of educational opportunity eludes definition, with proposals ranging from securing the absence of overt discrimination based 
on race or gender to the far more ambitious goal of eliminating race, gender, and class differences in educational outcomes" (pp. ix).

This state of affairs is the starting point of our paper, which contributes to the literature in three ways: first, building on the literature on equality of opportunity that has recently flourished in the area of social choice and normative economics, it proposes a definition of equality of educational opportunities. Second, the paper develops a methodology in order to test for the existence of equality of opportunity in a given distribution and to rank distributions according to equality of opportunity. Third, we present empirical evidence on the degree of equality of educational opportunity in the Italian university system.

The theory of equality of opportunity that has been developed recently in the area of normative economics goes far beyond the ideas of non discrimination and absence of legal barriers. On the other hand, it does not require equality of final achievements for individuals of different race, gender or social background. Rather, after the influential contributions by Arneson (1989), Barry (1991), Cohen (1989), Dworkin (1981), Roemer (1993, 1998) and Sen (1980), this literature has explored the conception of equality of opportunity as "leveling the playing field" according to which society should split equally the means to reach a valuable outcome among its members; once the set of opportunities have been equalized, which particular opportunity, the individual chooses from those open to her, is outside the scope of justice. As Roemer (1998) puts it, "in the notion of equality of opportunity there is a before and an after: before the competition starts opportunities must be equalized, but after it begins individuals are on their own". Ex ante inequalities, and only those inequalities, should be eliminated or compensated for by public intervention. Translated in terms of inequality measurement, this means that ex ante inequalities (i.e. inequalities in the set of opportunities open to individuals) are inequitable while ex post inequalities (i.e., inequalities in the final achievements) are not necessarily inequitable.

There is an extensive literature concerned with the measurement of inequality of opportunity, with both a theoretical and an empirical flavor. For theoretical models see, among others, Arlegi and Nieto (1999), Bossert et al. (1999), Herrero (1997), Herrero et al. (1998), Kranich (1996, 1997, 2003), Ok (1997), Ok and Kranich (1998), Savaglio and Vannucci (2007), Weymark (2003). In these models each individual is endowed with a given (abstract) set of opportunities and the society is represented as a profile of opportunity sets. Therefore, the problem of measuring the degree of opportunity inequality is handled by characterizing inequality rankings of profiles of opportunity sets. This approach is surely correct in principle; however, its empirical implementation is severely constrained by data limitation. Typically, the ex-ante opportunities open to individuals are not observable, while the actual choices are. Hence, a model able to infer the ex ante opportunities from some observable variables is needed. The contributions by Roemer (1998), Betts and Roemer (2003), Roemer et al. (2003), Aaberge et al. (2003), which focus on the design of opportunity egalitarian policies, and the contributions by Bourguignon et al. (2003), Goux and Maurin (2003), Checchi and Peragine (2005), Dardanoni et al. (2006), Lefranc 
et al. (2006 a,b), O'Neill et al. (1999), Peragine (2002, 2004, 2005), RuizCastillo (2000) and Villar (2006), which instead focus on the measurement of inequality of opportunity for income, are in this line.

In this paper we build on the approaches developed by Peragine $(2004,2005)$ and by Lefranc et al. (2006 a,b). We focus on the equality of educational opportunities for individuals of different social backgrounds and ask the following questions: when are educational opportunities of individuals of different backgrounds equalized? How to rank different systems according to the degree of opportunity inequality they exhibit?

All the literature on opportunity inequality mentioned before revolves around the idea that (i) individual outcomes (income, educational achievements, etc.) are determined by two classes of variables: circumstances, which include all the factors outside the sphere of individual responsibility, and effort, including all the factors for which the individual is held responsible and that (ii) a measure of opportunity inequality can be obtained by measuring that portion of outcome inequality which is explained or determined by differences in circumstances. Then, the approaches used differ from each other in the techniques the authors propose to capture such an effect.

Now, the application of such a conceptual framework to the educational opportunities is problematic for several reasons.

A first difficulty arises by arguing that the distinction between circumstances and effort is not relevant in education (De Villé, 2003): is it reasonable to hold pupils accountable for their effort, given that they are not adults? Can we consider them to be fully able to take autonomous and informed decisions? During a large fraction of their school years, individuals are not considered to be perfect judges for themselves and, in fact, in many aspects of social life, a paternalistic approach is adopted with respect to children and teenagers. If we push this argument far enough, we would conclude that circumstances account for virtually all the variability of educational outcomes, and that the policy objective must be one of equalizing pupils' educational achievements. Along those lines, we believe that this objection makes sense with respect to the general problem of measuring opportunity inequality in education. However, in this paper we focus on the university system, where students are adult citizens, and therefore personal commitment and effort can be considered to be under their control. ${ }^{1}$

A second question related to the partition in circumstances and effort concerns the status of innate abilities. Innate talents and abilities are exogenous variables, chosen by nature and not by individuals. That is to say that they belong to the set of circumstances. Thus, according to the opportunity egalitarian ethics, society should compensate pupils for the different endowments in talents in order to neutralize their effect on the final achievement. However, such a prescription seems in contrast with a role generally attributed to the educational system in a society which seeks to be meritocratic: the role of selecting talents and "signaling" those talents, together with the acquired competencies, to the

\footnotetext{
${ }^{1}$ For a discussion on this issue see Waltenberg (2006).
} 
labour market. In general, efficiency considerations suggest much caution in designing measures intended to neutralize the effects of different abilities. Hence, the inclusion of talents and abilities within the set of circumstances in the realm of education seems particularly problematic. In our empirical specification the individual circumstances are represented only by family background, measured by the parental education; hence, we implicitly assume that talents are part of the individual sphere of responsibility.

A final question refers to the definition of individual achievement. A simple application of the EOp scheme to the school system would imply evaluating the effects of circumstances on the individual educational outcomes (years of schooling, test scores, graduation marks, etc.). However, even without denying that education has a value per se, one could also argue that education has a indirect or instrumental value and that the final achievements of education should be expressed by some indicators of the value assigned to education in the labour market. Education can be seen as an important determinant of future earning capacity of individuals and, thereby, of their future well-being. To defend such a consequentialist view of education, consider that this kind of reasoning is perfectly in tune with the economic role recognized to education in mainstream economic theory, namely the one that sees education essentially as an investment in human capital (Becker, 1993). Hence, it seems coherent with such an approach to evaluate different education systems, also in equity terms, by looking at their effects on the earnings of individuals, for these are the final achievements of an investment in education. Consequently, in our empirical application we propose two different specifications of the educational outcomes: first we study the extent of equality of opportunity with respect to academic achievements as measured by the probability of graduation and the actual graduation marks; second we study the transition of university graduates to the labour market and analyze the equality of opportunity with respect to actual earnings.

Let us now summarize the strategy we propose in the paper.

Consider a given population and a distribution of a particular form of individual outcomes (income, educational achievements, etc.) which is assumed to be determined by two classes of variables: circumstances and effort. Now partition the population into types, a type being a group of people endowed with the same circumstances. If we assume that the individual outcome is determined only by circumstances and effort, and that the distribution of effort is independent from circumstances, then all the variation of outcomes (say, incomes or test scores) of individuals within a given type would be assumed to be caused by differential personal effort. That is to say, the outcome distribution conditional to circumstances can be interpreted as the set of outcomes open to individuals with the same circumstances: the opportunity set - expressed in outcome terms - open to any individual in that type. Hence, comparing the opportunity sets of two individuals endowed with different circumstances amounts to comparing their type conditional distributions. Roughly speaking, inequality of opportunities in this scenario is revealed by inequality between types distributions.

Exploiting this idea we first propose different definitions of equality of op- 
portunity in education. Then, we provide testable conditions with the aim of (i) testing for the existence of EOp in a given distribution and (ii) ranking distributions on the basis of EOp. Definitions and conditions resort to standard stochastic dominance tools. Dominance conditions are therefore tested by using non-parametric tests of stochastic dominance developed by Beach and Davidson (1983) and Davidson and Duclos (2000).

We then propose an empirical analysis of equality of opportunity in the Italian university system using different surveys over the period 2000-2004 and compare two Italian macro-regions, South and North-Centre. This choice is suggested by the existence of an empirical literature which shows (i) higher degree of social mobility and equality of opportunity for income in the northern regions (Checchi and Dardanoni, 2002 and Checchi and Peragine, 2005) and, with respect to school achievements, (ii) a stronger effect of the family background on the test scores of high school students in the South (Checchi and Peragine, 2005 Checchi et al., 2007). Our empirical application intends to add new evidence on this issue by focusing specifically on the highest education segment.

Our empirical results show that the strong family effect detected by previous studies is also preserved both in tertiary education and in the transition of graduates to the labour market. It also reveals that the inequality of opportunity is stronger when looking at the effects of family background on graduation marks and drop out rates than when examining graduates' incomes. Moreover, it turns out that the inequality of opportunity is more severe in the South than in the regions of North-Centre particularly in the case of income distributions.

The rest of the paper is organized as follows. Section 2 discusses our characterization of equality of educational opportunity. We first propose a definition of equality of educational opportunities; we then develop a comprehensive model that allows to test for equality of opportunity and to rank distributions according to educational EOp. In Section 3 we provide an empirical analysis of equality of opportunity for higher education in Italy. Some concluding remarks appear in Section 4.

\section{Equality of educational opportunities}

\subsection{The analytical framework}

We have a society of individuals, where each individual is completely described by a list of traits partitioned into two different classes: traits beyond the individual responsibility, represented by a person's set of circumstances $O$, belonging to a finite set $\Omega=\left\{O^{1}, \ldots, O^{n}\right\}$, with $|\Omega|=n$; and factors for which the individual is fully responsible, effort for short, represented by a variable $e \in \Theta$. Different partitions of the individual traits into circumstances and effort correspond to different notions of equality of opportunity. The value of $e$ actually chosen by each individual is unobservable. Individual outcome is generated by a function $g: \Omega \times \Theta \rightarrow \Re_{+}$, so that $x=g(e, O)$, with $x \in[0, z] \subseteq \Re_{+}$. We do not know the form of the function $g$, hence we do not make any assumption about the 
degree of substitutability or complementarity between effort and circumstances; this issue, which is indeed important at an empirical level, is not specified here in order to keep the approach as general as possible. We assume, however, that the function $g$ is fixed and is the same for all individuals.

A society outcome distribution is represented by a cumulative distribution function $F: \Re_{+} \rightarrow[0,1]$, belonging to the set $\Psi$. We can partition any given population into $n$ subpopulations, each representing a class identified by the variable $O$. For $O^{i} \in \Omega$, we call "type $i$ " the set of individuals whose set of circumstances is $O^{i}$. Within type $i$ there will be a distribution of outcomes, with density $f_{i}(x)$, c.d.f. $F_{i}(x)$, population share $q_{i}^{F}$ and average $\mu_{i}^{F}$. Hence, for all $O^{i} \in \Omega, F_{i}(x)$ is the outcome distribution conditional to circumstances $O_{i}$.

The distributions of income will differ across types; note however that the distribution function is a characteristic of the type, not of any individual. The distribution $F^{i}(x)$ represents the set of outcome levels which can be achieved by exerting different degrees of effort - starting from the circumstances $O_{i}$. That is to say, the distribution $F^{i}(x)$ is a representation of the opportunity set - expressed in outcome terms - open to any individual endowed with circumstances $O_{i}$. Hence, comparing the opportunity sets of two individuals endowed with circumstances $\left(O_{i}, O_{j}\right)$ amounts to comparing their type relevant outcome distributions $F_{i}(x), F_{j}(x)$. Moreover, evaluating the distribution of opportunity sets among individuals in a society amounts to evaluate the set of distributions $\Phi=\left\{F^{1}(x), \ldots, F^{n}(x)\right\}$. In the following sections we exploit this idea ${ }^{2}$.

\subsection{Defining equality of opportunity}

We first introduce a general definition of equality of opportunity.

Definition 1 Given a set of distributions $\Phi=\left\{F^{1}(x), \ldots, F^{n}(x)\right\}$, there is Equality of Opportunity if and only if, for any pair of distributions $F_{i}, F_{j} \in \Phi$, neither $F_{i}$ is preferred to $F_{j}$, nor $F_{j}$ is preferred to $F_{i}$.

To give content to the definition above one needs to define a preference relation on the set of type conditional distributions. We assume that such a preference relation can be represented by an evaluation function $V: \Phi \rightarrow \Re_{+}$, and we impose some conditions on such function.

A first assumption concerns the aggregation issue, that in this case is a within-type aggregation. We impose a utilitarian structure. Hence, we propose the following additive evaluation function $V$ for a given type $i$ :

$$
V\left(F_{i}\right)=\int_{0}^{z} U_{i}(x) f^{i}(x) d x
$$

where $U_{i}:[0, z] \rightarrow \Re_{+}$is the evaluation function of an individual in type $i$; it is assumed to be twice differentiable (almost everywhere) in $x$.

\footnotetext{
${ }^{2}$ For a different approach, which instead focuses on the outcome distributions within the groups of people who exert the same degree of effort see Roemer (1998), Peragine (2002) and Checchi and Peragine (2005).
} 
Next, we introduce a common monotonicity assumption, which guarantees that social welfare does not decrease as a result of an outcome increment, whatever the type:

$$
(C .1) \forall i \in\{1, \ldots, n\}, \frac{d U_{i}(x)}{d x} \geq 0, \forall x \in[0, z] .
$$

Next, we assume that our evaluation function is inequality averse. We require within-type strict inequality aversion:

$$
(C .2) \forall i \in\{1, \ldots, n\}, \frac{d^{2} U_{i}(x)}{d x^{2}}<0, \forall x \in[0, z] .
$$

Alternatively, we could require our function $V$ to be indifferent to outcome inequality within the same type, therefore assuming within-type inequality neutrality:

$$
(C .3) \forall i \in\{1, \ldots, n\}, \frac{d^{2} U_{i}(x)}{d x^{2}}=0, \forall x \in[0, z] .
$$

This condition says that a reduction in outcome inequality within a type, which leaves the mean of the type unchanged, has no welfare effects. Note that this welfare condition implies that the function $U_{i}$ is affine.

Conditions $^{3}$ (C.1), (C.2) and (C.3) identify several classes of individual utility functions $U$ that implicitly define classes of evaluation functions $V$. Now we define three such classes: the class of types evaluation functions $V$ constructed as in (1) and with utility functions satisfying conditions (C.1) is denoted by $\mathbf{V}_{1}$; the class of evaluation functions constructed as in (1) and with utility functions satisfying conditions (C.1) and (C.2) is denoted by $\mathbf{V}_{12}$; the class of types evaluation functions constructed as in (1) and with utility functions satisfying conditions (C.1) and (C.3) is denoted by $\mathbf{V}_{13}$.

The next step consists in deriving suitable criteria for choosing among opportunity sets by requiring unanimous agreement among these classes. Hence, we have the following definitions of a preference relation over the set $\Phi$ of types distribution functions.

Definition 2 For all $F_{i}, F_{j} \in \Phi$,

$$
\begin{aligned}
& F_{i} \succ_{V 1} F_{j} \text { if and only if } V\left(F_{i}\right) \succ V\left(F_{j}\right) \text { for all } V \in \mathbf{V}_{1} \\
& F_{i} \succ_{V 12} F_{j} \text { if and only if } V\left(F_{i}\right) \succ V\left(F_{j}\right) \text { for all } V \in \mathbf{V}_{12} \\
& F_{i} \succ_{V 13} F_{j} \text { if and only if } V\left(F_{i}\right) \succ V\left(F_{j}\right) \text { for all } V \in \mathbf{V}_{13}
\end{aligned}
$$

\footnotetext{
${ }^{3}$ While in the paper the function $V$ is interpreted as representing the preference relation of a social planner, it could also be interpreted as an individual utility function over a lottery with distribution $F_{i}(x)$ and support $[0, z]$. Hence, the function $V$ would represent the individual preferences over the opportunity sets. In this case, conditions $(C .2)$ and $(C .3)$ are to be interpreted as requirements of strict risk aversion and risk neutrality, respectively.
} 
Standard results in inequality theory allow to identify the distributional conditions corresponding to the welfare criteria above.

The ranking $\succ_{V 1}$ is equivalent to first order stochastic dominance $\left(\succ_{F S D}\right)$ :

Remark 3 For all $F_{i}, F_{j} \in \Phi, F_{i} \succ_{V 1} F_{j}$ if and only if

$$
F_{i} \succ_{F S D} F_{j} \Longleftrightarrow F_{j}(x) \geq F_{i}(x) \text { for all } x \in[0, z]
$$

with strict inequality for some $x$.

The ranking $\succ_{V 12}$ is equivalent to second order stochastic dominance $\left(\succ_{S S D}\right)$ :

Remark 4 For all $F_{i}, F_{j} \in \Phi, F_{i} \succ_{V 12} F_{j}$ if and only if

$$
\left.F_{i} \succ_{S S D} F_{j} \Longleftrightarrow \int_{0}^{t} F_{j}(x) d x \geq \int_{0}^{t} F_{i}(x)\right] d x \text { for all } t \in[0, z]
$$

with strict inequality for some $x$.

As it is well known, second order stochastic dominance is equivalent to Generalized Lorenz dominance (see Shorrocks, 1983).

Finally, the ranking $\succ_{W 13}$ is equivalent to higher expected value.

Remark 5 For all $F_{i}, F_{j} \in \Phi, F_{i} \succ_{W 13} F_{j}$ if and only if $\mu_{i}>\mu_{j}$.

Given the distributional conditions discussed above, we can now introduce some criteria to test for the existence of EOp.

\subsection{Testing for the existence of EOp}

In this section we make use of the definition of equality of opportunity and the criteria derived in the previous section in order to identify empirical tests for the existence of equality of opportunity in a distribution of opportunity sets ${ }^{4}$.

We start with the strongest definition of EOp, requiring that individuals face identical prospects of outcome, regardless of their circumstances

Definition 6 Strong EOp. There is EOp if and only if, $\forall F_{i}, F_{j} \in \Phi$,

$$
F_{i}(x)=F_{j}(x), \forall x \in[0, z]
$$

Since the condition above is extremely demanding and will be violated in most case we turn to less demanding conditions.

The first test is based on the preference relation $\succ_{V 13}$ :

Definition 7 Weak EOp. There is EOp if and only if, $\forall F_{i}, F_{j} \in \Phi$,

$$
F_{i} \nsucc_{V 13} F_{j} \text { and } F_{j} \nsucc_{V 13} F_{i} \Leftrightarrow \mu_{i}=\mu_{j}
$$

\footnotetext{
${ }^{4}$ Here, we follow the approach proposed by Lefranc et al. (2006 a,b).
} 
A second test is based on the preference relation $\succ_{V 1}$ :

Definition 8 EOp1 (EOp of the first order). There is EOp if and only if, $\forall F_{i}, F_{j} \in \Phi$,

$$
F_{i} \nsucc_{V 1} F_{j} \text { and } F_{j} \nsucc_{V 1} F_{i} \Leftrightarrow F_{i} \nsucc_{F S D} F_{j} \text { and } F_{j} \nsucc_{F S D} F_{i}
$$

The next test is based on the preference relation $\succ_{V 12}$ :

Definition 9 EOp2 (EOp of the second order) There is EOp if and only if, $\forall F_{i}, F_{j} \in \Phi$,

$$
F_{i} \nsucc_{V 12} F_{j} a n d F_{j} \nsucc_{V 12} F_{i} \Leftrightarrow F_{i} \nsucc_{S S D} F_{j} \text { and } F_{j} \nsucc_{S S D} F_{i}
$$

These tests allow us to conclude whether in a given distribution there is EOp or not according to the different definitions introduced. In the next section we address the problem of ranking distributions of opportunity set on the basis of EOp.

\subsection{Ranking distributions of opportunity sets}

Our aim is to derive welfare criteria and dominance condition in analogy with the analysis conducted in the previous section. However, here the criteria have to be defined over the set of distributions $\Psi$. Again, we assume that a preference relation over $\Psi$ can be represented by a social evaluation function $W: \Psi \rightarrow \Re_{+}$. A generalization of the evaluation function $V$, discussed in the previous section, to the case of income distributions, which can be decomposed across homogeneous sub-groups, is obtained by aggregating the welfare of each type, weighted by the relevant population share, and using type-specific utility functions. If we opt for an additive aggregation of the types welfare, then we obtain the following utilitarian social evaluation function ${ }^{5}$ (SEF):

$$
W(F)=\sum_{i=1}^{n} q_{i}^{F} \int_{0}^{z} U^{i}(x) f^{i}(x) d x
$$

$\mathrm{We}^{6}$ now try to capture the basic intuition beyond the opportunity egalitarian ethics, by selecting different classes of utility functions $<U_{1}(x), \ldots, U_{n}(x)>$.

\footnotetext{
${ }^{5}$ This utilitarian social welfare approach to the evaluation of equality of opportunity was first proposed by Van de gaer (1993)

${ }^{6}$ Also in the current scenario, the interpretation of the evaluation function $W$ is ubiquitous. In fact, the SEF proposed above can be interpreted as:

$$
W_{F}=\sum_{i=1}^{n} \operatorname{Pr}\left\{k \in O^{i}\right\} E\left[U^{i}(x) \mid k \in O^{i}\right]
$$

where, with a slight abuse of notation, $\operatorname{Pr}\left\{k \in O^{i}\right\}$ is the probability for an individual $k$ of being endowed with the circumstances $O^{i}$ and, therefore, of facing the prospect $F_{i}(x)$; $E\left[U^{i}(x) \mid k \in O^{i}\right]$ is the expected utility associated to type $i$. Hence, our SEF can be expressed as a weighted sum of the expected utility associated to each type weighted by the probability to belong to that type.
} 
First, we could impose on the types specific functions $U_{i}$ properties $(C .1),(C .2)$ and (C.3) already introduced in the previous section, which are not type-specific. In addition, we now formulate some type dependent properties.

First, we define a condition expressing inequality aversion between the opportunity sets. The condition stating between-types inequality aversion is the following:

$$
\text { (C.4) } \frac{d U^{i}(x)}{d x} \geq \frac{d U^{i+1}(x)}{d x}, \forall i \in\{1, \ldots, n-1\}, \forall x \in[0, z],
$$

which says that the marginal increase in welfare due to an increment of income is a decreasing function of circumstances ${ }^{7}$.

To the properties already introduced we now add the following condition $^{8}$ :

$$
\text { (C.5) } \forall i, j \in\{1, \ldots, n\}, U^{i}(z)=U^{j}(z)
$$

where $z$ is the maximum possible income. By introducing condition (C.5) any affine transformation such as, for example, $U^{i} \rightarrow a^{i}+b U^{i}$, is supposed to be able to affect the results of social comparisons ${ }^{9}$. This requirement is necessary in a context with different types population.

We now define two classes of social evaluation functions: the class of social evaluation functions constructed as in (2) and with utility functions satisfying conditions (C.1), (C.3), (C.4) and (C.5), denoted by $\mathbf{W}_{E O P 1}$; the class of social evaluation functions constructed as in (2) and with utility functions satisfying conditions (C.1), (C.4) and (C.5), denoted by $\mathbf{W}_{E O P 2}$.

The next step consists in deriving suitable welfare and distributional conditions by requiring unanimous agreement among these classes.

Definition 10 For all $F, G \in \Psi$,

$$
\begin{aligned}
& F \succeq_{E O P 1} G \text { if and only if } W(F) \geq W(G) \text { for all } W \in \mathbf{W}_{E O P 1} \\
& F \succeq_{E O P 2} G \text { if and only if } W(F) \geq W(G) \text { for all } W \in \mathbf{W}_{E O P 2}
\end{aligned}
$$

Thus, we turn to identify a range of tests which, if successful, will ensure welfare dominance for appropriate classes of SEFs. The aim of the analysis is the following: given a class of utility functions $U_{i}(x)$ expressing our ethical concerns, we seek conditions, expressed in terms of distribution functions $F_{i}(x)$ and $G_{i}(x)$ and population shares $q_{i}^{F}$ and $q_{i}^{G}$, which are necessary and sufficient for welfare dominance according to the criteria defined above.

We first propose the following distributional condition:

\footnotetext{
${ }^{7}$ Conditions $(C .1),(C .3)$ and $(C .4)$ entail cardinal unit comparability (cf Sen, 1970).

${ }^{8} \mathrm{An}$ analog condition is introduced by Jenkins and Lambert (1993) in the context of income inequality in presence of differences in needs and in order to extend the "sequential generalized Lorenz dominance" to the case of distributions with different types partitions.

${ }^{9}$ By adding condition (C.5) we pass from cardinal unit comparability to cardinal full comparability (cf Sen, 1970).
} 
Theorem 1 (Peragine, 2004). For all $F, G \in \Psi, F \succeq_{E O P 1} G$ if and only if

$$
\sum_{i=1}^{k} q_{F}^{i} \mu_{F}^{i} \geq \sum_{i=1}^{k} q_{G}^{i} \mu_{G}^{i}, \forall k \in\{1, \ldots, n\}
$$

This test can be interpreted as a second order stochastic dominance (generalized Lorenz dominance) applied to the distribution of the type means weighted by the relevant population shares: $\left(q_{1}^{F} \mu_{1}^{F}, \ldots, q_{n}^{F} \mu_{n}^{F}\right)$.

Note that by applying such a test, we are implicitly making the following operations: we evaluate (i) the opportunity set of each type by the weighted mean $q_{i}^{F} \mu_{i}^{F}$ and (ii) the distribution of opportunity sets by the generalized Lorenz criterion.

Notice that if we follow the individual "risk" interpretation, then the solution we are proposing corresponds to evaluate the opportunity set of an individual endowed with circumstances $O_{i}$ by the expected value of the types she belongs to $\left(\mu_{i}^{F}\right)$ multiplied by the probability of belonging to the specific type $q_{i}^{F}$; and to rank the profiles of such opportunity sets according to second order dominance.

The second distributional condition we obtain is the following:

Theorem 2 For all $F, G \in \Psi, F \geq_{I O P 2} G$ if and only if

$$
\sum_{i=1}^{k} q_{i}^{F} F_{i}(x) \geq \sum_{i=1}^{k} q_{i}^{G} G_{i}(x), \forall x \in[0, z], \forall k \in(1, \ldots, n)
$$

Proof. See the Appendix.

This theorem characterizes a sequential first order stochastic dominance condition, where each type distribution is weighted by the relevant population share. This condition dictates the following procedure: take first the lowest type of the two distributions and check for dominance; then we add the second lowest type, then the third lowest type and so on, until all the population is included, performing the dominance check at every stage. We have to perform $n$ different tests, starting form the lowest type, until all types are merged. If these tests are always positive then we have welfare dominance for the family $\mathbf{W}_{E O P 2}$ and the converse is also true.

We therefore implicitly make the following operations: we evaluate (i) the opportunity set of each type by the weighted c.d.f. $q_{i}^{F} F_{i}(x)$ and (ii) the distribution of opportunity sets by the Generalized Lorenz criterion. Hence the difference with the condition obtained in Theorem 1 lies in the evaluation of the individual opportunity set: in the criterion $\geq_{I O P 1}$ it is evaluated by the weighted expected value, while in the criterion $\geq_{I O P 2}$ each opportunity set is evaluated by looking at the entire weighted distribution. As for the ranking of profiles of opportunity sets, the distributive criterion remains the same.

A final remark is in order. We have focused on unanimous preference orderings for classes of opportunity egalitarian social decision makers rather than on purely (opportunity) inequality criteria. Consequently, the distributional conditions obtained are expressed in terms of means, c.d.f. and generalized Lorenz dominance, rather than simple Lorenz dominance. 


\subsection{A summary}

Let us summarize the conditions and the criteria discussed and characterized so far.

Remark 11 As for the test of existence of equality of opportunity in a given distribution $F$, we have proposed the following tests

$$
\begin{aligned}
& \text { (1) Weak EOp } \quad \Rightarrow \quad \forall(i, j), \mu_{i}=\mu_{j} \\
& \text { (2) Strong EOp } \quad \Rightarrow \quad \forall(i, j), F_{i}(x)=F_{j}(x), \forall x \in[0, z] \\
& \text { (3) EOp1 } \quad \Rightarrow \quad \forall(i, j), F_{i} \nsucc_{F S D} F_{j} \text { and } F_{j} \nsucc_{F S D} F_{i} \\
& \text { (4) EOp2 } \Rightarrow \quad \forall(i, j), F_{i} \nsucc_{S S D} F_{j} \text { and } F_{j} \nsucc_{S S D} F_{i}
\end{aligned}
$$

Remark 12 As for the ranking of different distributions $(F, G)$ according to equality of opportunity, we have proposed the following criteria. For all F, $G$ $\in \Psi$

$$
\text { (5) } F \geq_{I O P 1} G \Leftrightarrow \sum_{i=1}^{k} q_{i}^{F} \mu_{i} \geq \sum_{i=1}^{k} q_{i}^{G} \mu_{i}, \forall k
$$

$$
\text { (6) } F \geq_{I O P 2} G \Leftrightarrow \sum_{i=1}^{k} q_{i}^{F} F_{i}(x) \geq \sum_{i=1}^{k} q_{i}^{G} G_{i}(x), \forall x, \forall k
$$

\section{The empirical analysis: equality of opportu- nity in the Italian higher education system}

In this section we apply the theoretical framework proposed in the previous section with the aim of analyzing equality of opportunity in the Italian higher education system. We examine whether final graduate students outcomes and their salaries distributions are characterized by equality of opportunity. Since we strongly believe that placement in the labour market should also be considered in order to fully evaluate individual tertiary education outcome, we analyze both the income distribution after three years from graduation and the income distribution of those who have held a degree for more than three years. The choice of three years as a threshold is related to the specific design of the survey of graduates we use in the empirical application (individuals are interviewed after three from the completion of their studies). In our analysis individual circumstances are represented by parental education. Moreover, since our analysis also extends to consider the existence of regional disparities in Italy, the conditional distributions of two Italian macro-regions, the North-Center and the South, are compared and ranked according to different notions of EOp. In what follows we present the data and the empirical methodology, finally we discuss the results. 


\subsection{Data description}

In this application we use three outcome variables: graduation marks ${ }^{10}$, net monthly income after three years from graduation and annual disposal income earned after more than three years from graduation, which we simply call income. On the other hand, parental education is measured by the highest educational attainment in the couple of parents and is divided in four classes. We therefore allocate the individuals in four types, according to parental education, as follows: the first type corresponds to primary school degree; the second type to lower secondary school degree; the third type to upper secondary degree; finally, graduates who have at least one of the parents with a bachelor (or higher degree) belong to the fourth type. Furthermore, the Italian regions are divided in two macro-regions as follows: the North-Center comprehends Piemonte, Lombardia, Veneto, Liguria, Trentino, Friuli, Emilia Romagna, Toscana, Umbria, Marche while the South includes Lazio, Abbruzzo, Molise, Campania, Puglia, Basilicata, Calabria, Sicilia, Sardegna. ${ }^{11}$

Information on graduation marks and net monthly income after three years from graduation are taken from "Indagine sull'Inserimento Professionale dei Laureati" (IIPL, hereafter), a survey on the transition from college to work of a representative sample of Italian graduates conducted by the National Statistical Office (Istat) in 2004; whereas data on annual disposal income of individuals who have held a degree for longer than three years are drawn from the Bank of Italy "Survey of Household Income and Wealth" (SHIW, hereafter).

The IIPL contains information on individuals who graduated in 2001 and covers school curriculum, labour market experience in the three years after graduation, job search activities, household and individual information. The interviewed sample corresponds to about the 17 percent of the population of graduates of 2001. The sample dimension is considerable as the ratio between sampled person and the universe is roughly 1:6. In total the sample consists of about 30,000 individuals (41.4\% from Southern and 58.6\% from North-Center Universities). Differently, the SHIW contains detailed information on household composition, age, education, labour market variables, incomes (for individuals and households), savings, consumption and wealth, of Italian households and household members. This survey has been conducted regularly from the Bank of Italy since 1965. However, since we need information on the year of college completion we only consider the last three waves (2000, 2002 and 2004) available. We drop the panel component of those three waves and express income in terms of euro at 2000. In this sample the graduates who have completed their studies for at least four years are 1.795 (39\% in the South and $61 \%$ in the North). ${ }^{12}$

\footnotetext{
${ }^{10}$ In Italy the final graduation mark ranges from 66 to 110 cum laude, in this analysis the 110 cum laude was simply transformed in 111

${ }^{11}$ Note that we include Lazio among the Southern region in order to balance the number of observations between the two macro-regions. However, considering Lazio as a Southern or Northern region does not significantly change the results which are available from the authors upon request.

${ }^{12}$ We consider graduates people declaring to hold a short-course university degree ("diploma universitario"), a bachelor's degree, or a postgraduate qualification.
} 
Notice that while in the case of IIPL the sample is divided in North-Center and South with respect to the geographical location of the University attended, in the case of SHIW the macro-regions are defined on the basis of the individuals region of residence. In fact, because of internal mobility, the University site would not be a good proxy for geographical location after a long period from graduation.

Lastly, we acknowledge that, in order to investigate the academic performance, we must consider not only the students who succeeded and graduated but also those who failed their attempts to complete tertiary education. In order to do so, we use a parallel survey conducted by Istat on the transition from high school to college, "Indagine sull'Inserimento Professionale dei Diplomati" (this information is indeed not available in IIPL, where only graduates are interviewed). This survey conducted in 2001 collects information on students that completed high school in 1998. In order to take into account the drop-out rate we calculate the probability of dropping out after three years from matriculation for each type and macro-region. Hence, we add to the sample of graduates of the IIPL, in each type and region, a number of students with final mark equal to zero proportionally to the drop-out rate.

Notice also that in this analysis we ignore the fact that the data contained in those surveys do not concern the same individuals, information are matched on the basis of circumstances. Summary statistics follow in the Appendix.

\subsection{Statistical analysis and methodology}

Our samples allow to build outcome (i.e. final marks and income) distributions conditional on circumstances and perform a simple twofold analysis.

We assess equality of distribution as developed in Beach and Davidson (1983) and perform first and second order stochastic dominance tests using Davidson and Duclos (2000) methodology. The details of the tests implemented are illustrated in the Appendix.

In order to draw our conclusion we carry out the following empirical procedure, as described in Lefranc et al. (2006). We conduct a separate analysis for the two macro-regions and, for all the possible pairs of circumstances $i$ and $j$ within the same region, we perform four tests independently:

- Test (1) (Weak EOp): tests the null of equality of the means of the distribution of types $i$ and $j$;

- Test (2) (Strong EOp): tests the null of equality of the distributions of types $i$ and $j$;

- Test (3) (EOp1): tests the null of first order stochastic dominance of the distribution of type $i$ over $j$ and viceversa;

- Test (4) (EOp2): tests the null of second-order dominance of the distribution of type $i$ over $j$ and viceversa.

Then we pursue the following strategy:

- If the null of Test (1) or Test (2) is not rejected, we conclude that Weak or Strong EOp is satisfied. 
- If Test (3) or (4) accepts dominance of one distribution over the other but not the other way around, we say that equality of opportunity is violated.

- If Test (3) rejects dominance of each distribution over the other we say that equality of opportunity of the first order is supported.

- If Test (3) and (4) conclude that the two distributions dominate each other we give priority to the results of Test (2).

Accordingly, we proceed by comparing the results obtained for the two macro-regions.

The drawback of such approach is that it does not allow us to rank different situations in which we would reject equality of opportunity. Hence, in case we find evidence of inequality of opportunity we move to the second step of our analysis, that is we look for partial ranking of the distributions of opportunity sets in the two macro-regions. Hence, in order to do so, we rely on the dominance conditions characterized in Theorems 1 and 2 . We first verify the existence of the partial ranking $\geq_{I O P 1}$ by numerical comparison of the distributions of the type (weighted) means of the two regions [Test (5)]. Next, we apply the second criterion $\left(F \geq_{I_{O P 2}} G\right)$ by sequentially testing the following null hypotheses of first order stochastic dominance:

1. $q_{1}^{F} F_{1}(x) \leq q_{1}^{G} G_{1}(x)$;

2. $\Sigma_{i=1}^{2} q_{i}^{F} F_{i}(x) \leq \Sigma_{i=1}^{2} q_{i}^{G} G_{i}(x)$;

3. $\Sigma_{i=1}^{3} q_{i}^{F} F_{i}(x) \leq \Sigma_{i=1}^{3} q_{i}^{G} G_{i}(x)$;

4. $\Sigma_{i=1}^{4} q_{i}^{F} F_{i}(x) \leq \Sigma_{i=1}^{4} q_{i}^{G} G_{i}(x)$.

Where $F$ and $G$ are the conditional outcome distributions of North-Centre and South, respectively [Test (6)]. In these cases the same strategy of Test (3) is implemented.

\subsection{Empirical results}

In this section, we report the results of the tests of equality and stochastic dominance for the outcomes distributions conditional on four classes of parental education in the two macro-regions. Figures 1,2 and 3 show the cumulative distribution functions conditional on parental education of marks, income after three years from graduation and income.

As far as the graduation final marks is concerned a clear ranking of types emerges both in the North-Centre and in the South. The distribution of the fourth type dominates over the third, the third dominates over the second, the second dominates over the first. This visual ranking is strongly confirmed by the results of the tests of equality and stochastic dominance (see Table 2). The tests clearly indicate evidence of strong inequality of opportunity among individuals belonging to different types, both in the South and in the North-Centre. 
We have also repeated the same analysis conditioning the graduation marks on the type of upper secondary school attended ${ }^{13}$. Graduates have been therefore divided in two groups: the ones that attended a "liceo" and those who attended an "istituto" school type ${ }^{14}$. The results obtained in both groups confirm what described in the general unconditioned case (see Figure 1bis, i.e. the cumulative distributions function of final graduation marks for graduates that attended the "istituto" school type). This result is quite surprising. Indeed, it is generally recognized that in Italy students are streamed in different tracks more in consequence of their background than of their ability, and that, after enrolling in a track, the probability of entering in higher education still depends on family background (Checchi and Flabbi, 2007). Interestingly, our analysis shows that the effects of family background goes even further: after sorting the students according to their family backgrounds in different tracks, we find that the family of origin still matters for future academic performances within each track.

Turning to the dominance conditions, we notice that the weighted means are always higher in the South than in the North-Center for the graduation marks distributions (see Table 3): in the South marks are higher than in the North-Centre, and this is true for each type. However, results based on either the criterion $\geq_{I O P 1}$ or $\geq_{I O P 2}$ show a mixed pattern: the South dominates the North-Centre in all cases but the third. Hence, we cannot conclude for any dominance according to $\geq_{I O P}$ criteria in the case of mark distribution.

Notice that our main conclusion on final graduation marks does not change even when we condition the distribution on the area of academic specialization (Humanities and Social Science on one hand, Medicine, Science and Engineering on the other hand). Hence it is a quite robust result.

Turning the analysis to the income variables we notice that we are not able to make an explicit assessment just observing the cumulative distributions of income (Figure 2 and 3): in both cases the visual ranking is not very clear. Similarly the results of the statistical tests are not so definite as in the case of the graduation marks. In particular, in the case of the IIPL income we notice that the null of equivalence of means cannot be rejected at $5 \%$ of significance level in more cases in the North-Centre than in the South. From the tests of

\footnotetext{
${ }^{13}$ The type of secondary school attended is a crucial variable when studying the family background effect on Italian students' performances. In fact, the Italian upper secondary school is a tracked system, with three different path which can be freely chosen by the pupils at the age of 13 (i.e., by their parents): an academic oriented generalist education provided by high schools ( 5 years, called licei), a technically oriented education provided by technical schools (5 years, called istituti tecnici), and a vocational training offered by local schools organized at regional level (3 years, called istituti di formazione professionale). After a debated reform in 1969, students from any track are entitled to enrol in Colleges and Universities, conditional on having successfully completed 5 years of upper secondary schooling. However, each of these tracks predicts very different outcomes in terms of additional education acquired and labour market performance. As a matter of facts, more than $88 \%$ of students who graduate from licei enrol in a University as opposed to $17.8 \%$ of the students coming from the vocational track.

${ }^{14}$ Within the category "istituto" we included all the upper secondary schools different from "liceo".
} 
stochastic dominance (Table 2) we generally notice that there is more evidence of equality of opportunities in the North-Centre than in the South, i.e. we do not reach a clear cut conclusion on dominance in three cases in the NorthCentre and in only one case in the South. On the other hand, the results from inequality of opportunity comparisons allow us to reach a more definite result. Since (i) the weighted means are in all cases higher in the North-Centre than in the South (see Table 3) and (ii) the sequential first order stochastic dominance condition is satisfied (see Table 4) we can conclude that in the North-Centre there is more equality of opportunity than in the South when looking at levels of income three years after graduation.

These figures are consistent with the general view of less intergenerational mobility in the South than in the North of Italy. Also in this case we have repeated the exercise for conditioned income distribution. In particular, here we have studied separately the earnings of those who got medium-low graduation marks and the earnings of those who got medium-high gradation marks. Overall the results do not change when analyzing those two groups with respect to the general unconditioned case (see Figure 2bis, i.e. the cumulative distributions function of income after three years from graduation of individuals that received a medium-high final mark).

As far as the SHIW income is concerned the null of equivalence of means cannot be rejected at $5 \%$ of significance level in one more case in the South than in the North-Centre (see Table 1). The same evidence is shown in the tests for first and second dominance (see Table 2). Turning to the EOp ranking the figures obtained for income shows evidence of dominance of the North-Centre over the South only according to the $\geq_{I O P 1}$ criterion. Differently, the NorthCentre dominates the South in all the steps of the sequential procedure except the first. Therefore we conclude that the distributions of the macro-regions are not comparable according to $\geq_{I O P 2}$ in the case of income.

Summarizing, although some of our dominance conditions are not fully satisfied - and this is quite normal when using partial ranking - a general picture seems to emerge from the analysis of opportunity inequality for income: the southern regions have lower per-capita income accompanied by greater overall income inequality and by higher degree of opportunity inequality. ${ }^{15}$

In conclusion, our analysis shows that, while most of the parental background exerts its effect through favouring the educational attainment of the students, it keeps on playing a role in the labour market, independently from education. This could represent the impact that family networking plays in finding good jobs. Our evidence shows that this effect is stronger in the South than in the

\footnotetext{
${ }^{15}$ In the interpretation of the results, it should be reminded that our dominance criteria $\geq_{I O P 1}$ and $\geq_{I O P 2}$ reflect both distributive and aggregate aspects. It is possible that the dominance of the North-Centre over the South in income levels is driven by a average effect, rather than a pure inequality effect. Therefore, we have also performed pure inequality comparisons by Lorenz dominance test. In general, the results exhibit the same evidence found for the $\geq_{I O P 1}$ and $\geq_{I O P 2}$ dominace test for graduation marks. On the other hand, in the case of income distributions, Lorenz dominance tests show dominance of the South over the North-Centre in the first step of the sequential strategy, and dominance of the North-Centre over the South in the remaining steps.
} 
North-Centre.

\section{Concluding remarks}

Building on the existing literature on equality of opportunity, in this paper we have proposed a definition of equality of educational opportunities and a methodology to test for the existence of equality of opportunity in a given distribution and to rank distributions according to equality of opportunity. Moreover, we have provided an empirical application by studying the degree of equality of educational opportunity in the Italian university system.

We have compared two Italian macro-regions, South and North-Centre, according to equality of opportunity. In the first application we have focused on individual graduation scores, while in the second we have considered the distribution of incomes among Italian graduates; in both cases we have studied how these different individual achievements vary according to the family background, as measured by the level of parental education.

Our empirical results show a strong family effect on the performances of students in the university and on the transition of graduates in the labour market. In addition, our analysis reveals that the degree of opportunity inequality is stronger when looking at the effects of family background on graduation marks and drop out rates than when examining graduates' incomes. Moreover the inequality of opportunity turns out to be more severe in the South than in the regions of North-Centre especially for income distributions.

One wonders whether these effects may be addressed by appropriate policies. To begin with, our results point to the role of higher education policies.

In recent years the Italian university system has been involved in a deep process of reform, which has reduced the years of enrolment and has significantly enlarged the educational supply, in terms of possible curricula from which the students may choose. So far, the existing data show that this reform has increased the number of students enrolled in the university. Indeed, it would be extremely interesting to study the effect of such a reform from the equality of opportunity viewpoint: has the incidence of social background on the academic performance of students increased or decreased as effect of the reform? Unfortunately, the available data do not allow yet to draw conclusions on the effect of the reform. However, as soon as the relevant data will become available this will certainly be object of further investigation.

The same type of difficulty seems to emerge in the labour market. The effect of social origin plays a role in the earnings distributions, even among graduates with the same final marks and, again, this effect is stronger in the South than in the North. This could represent the impact of family networking in finding good jobs, as well as a reduced availability of good jobs in less technologically advanced areas. This greater obstacles and/or lack of adequate incentives in local labour markets can be linked to existing evidence of internal migration flows, which speaks of a sort of "brain drain", that is strong migration of high skilled workers from the South towards the Northern regions. While part of 
this migration is certainly explained by the different unemployment rates, existing studies show that the choice to migrate is specially concentrated among individuals with poor family background (see Coniglio and Peragine, 2007).

Finally, we would suggest some possible connection between what observed in the distributions of graduation scores of individuals coming from different social origin and what seen in the income distribution of the same social groups. Inequality of opportunities in the labour market may stem from the opaque working of the Italian labour market but also from some features of the university system. The evidence of generally higher marks in southern regions and of a strong effects of the family backgrounds on those marks, speaks of a university system that is hardly able to properly signal abilities and competencies of the students. But if the school system fails to be fully meritocratic and select according to abilities, then it is easier that other allocation mechanisms might prevail also in the labour market. Unfortunately, this does not come as a surprise in a country where more than $50 \%$ of the working population declares to have obtained the current job through recommendations of relatives or friends. 


\section{$5 \quad$ Tables and figures}

Figure 1. Graduate final marks c.d.f.
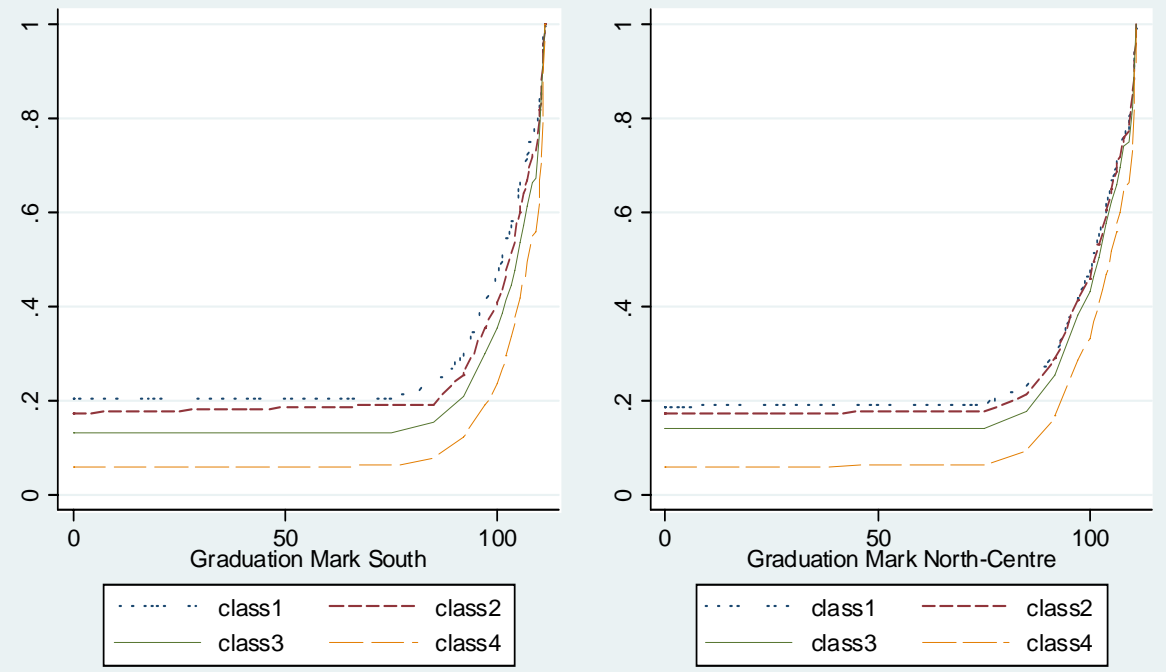

Figure 1bis. Graduate final marks c.d.f. conditional to school type ("istituto")
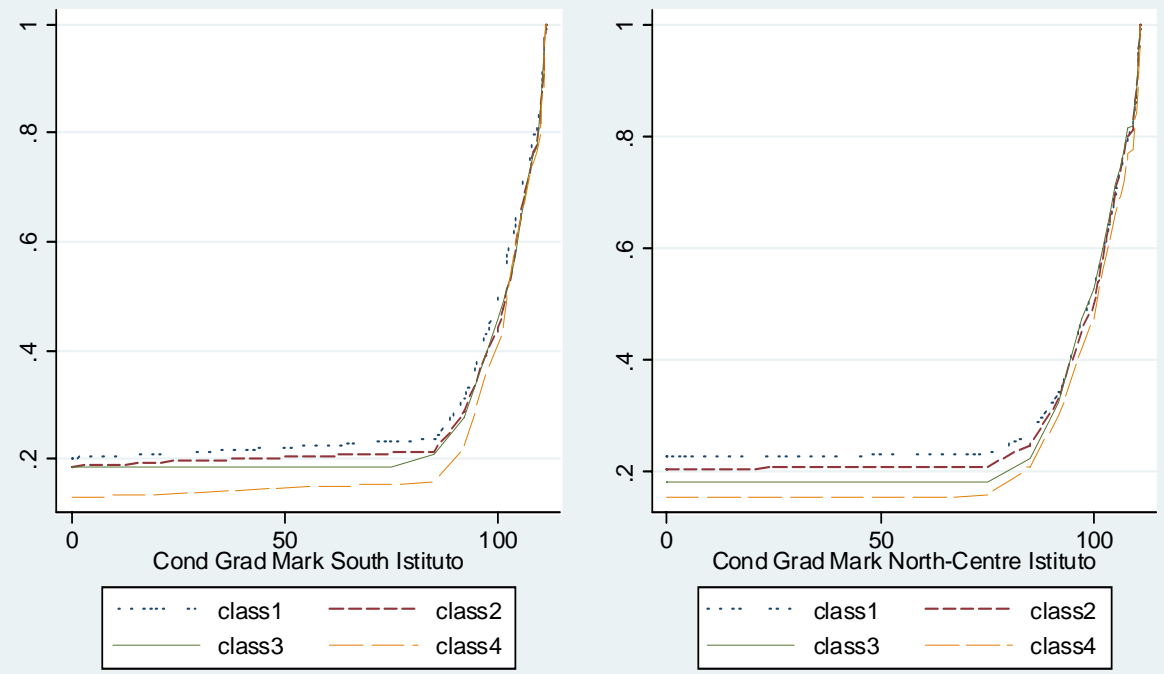
Figure 2. Income after 3 years from graduation c. d. f.
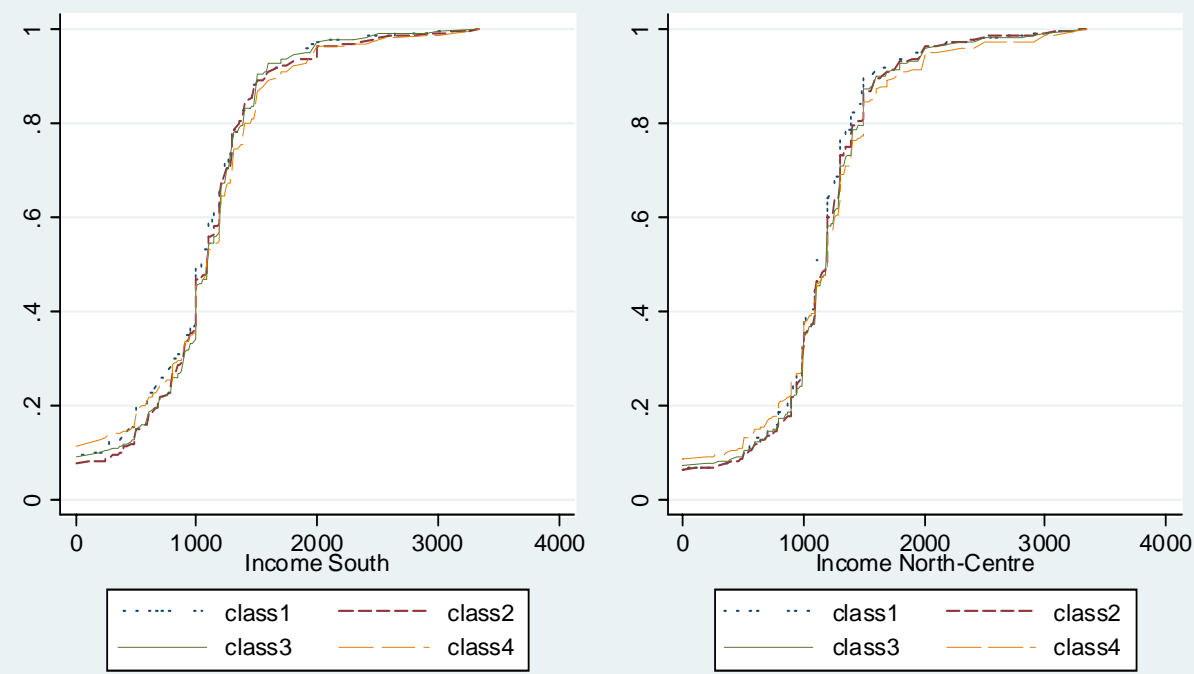

Figure 2 bis. Income after 3 years from graduation conditional to high marks c. d. f.
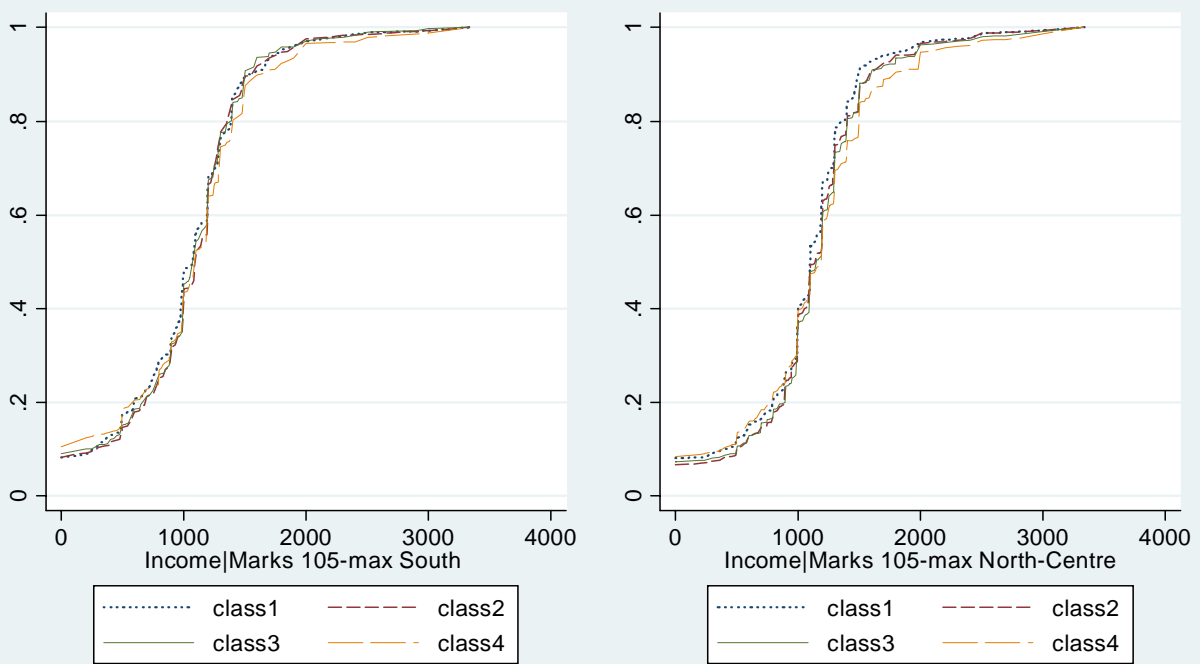
Figure 3. Income c.d.f.
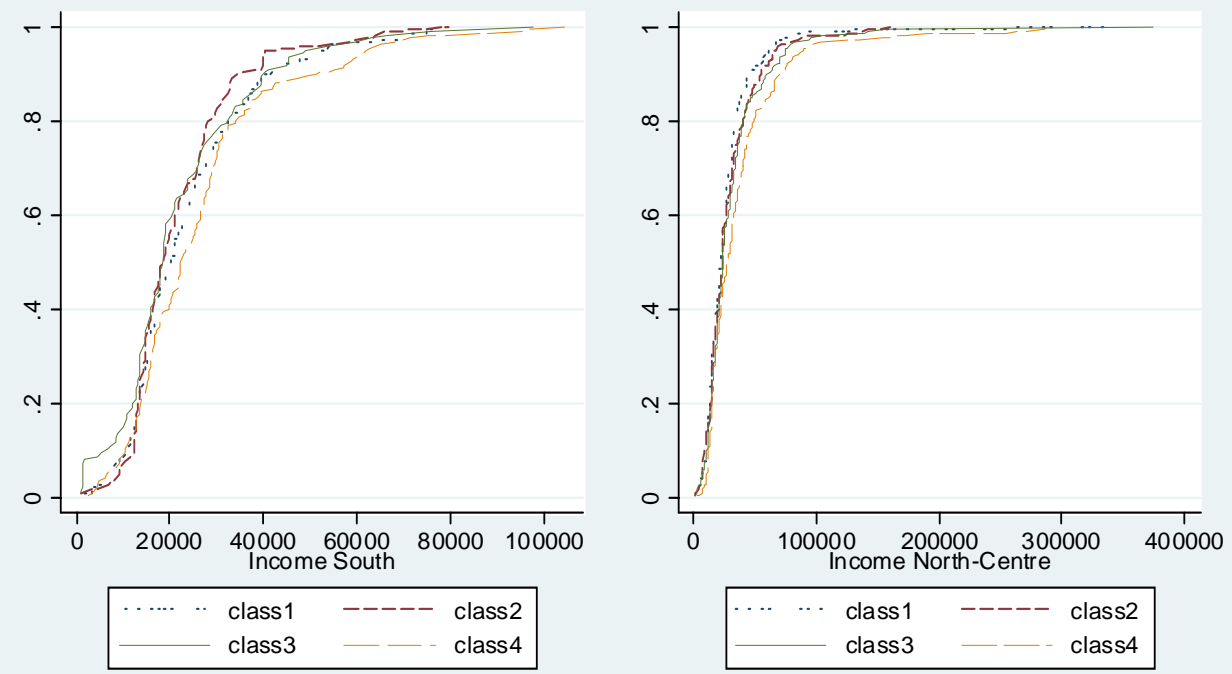

Table 1. Test (1) Weak EOp

\begin{tabular}{|l|l|l|l|l|l|l|l|l|}
\hline \multicolumn{7}{|c|}{ Graduation mark } \\
\hline & \multicolumn{7}{|c|}{ North-Centre } & \multicolumn{3}{|c|}{ South } \\
\hline & 1 & 2 & 3 & 4 & 1 & 2 & 3 & 4 \\
\hline 1 & - & $<^{* *}$ & $<^{*}$ & $<^{*}$ & - & $<^{*}$ & $<^{*}$ & $<^{*}$ \\
\hline 2 & & - & $<^{*}$ & $<^{*}$ & & - & $<^{*}$ & $<^{*}$ \\
\hline 3 & & & - & $<^{*}$ & & & - & $<^{*}$ \\
\hline 4 & \multicolumn{7}{|c|}{} & \multicolumn{7}{|c|}{-1} & & & & - \\
\hline \multicolumn{7}{|c|}{ Income after 3 years from graduation } \\
\hline 1 & - & $=^{*}$ & $<^{*}$ & $<^{*}$ & - & $<^{*}$ & $=^{*}$ & $<^{*}$ \\
\hline 2 & & - & $=^{*}$ & $=^{*}$ & & - & $<^{* *}$ & $<^{*}$ \\
\hline 3 & & & - & $=^{*}$ & & & - & $=^{*}$ \\
\hline 4 & & & & - & & & & - \\
\hline \multicolumn{7}{|c|}{ Income } & \\
\hline 1 & - & $=^{*}$ & $<^{*}$ & $<^{*}$ & - & $=^{*}$ & $=^{*}$ & $<^{* *}$ \\
\hline 2 & & - & $=^{*}$ & $<^{*}$ & & - & $=^{*}$ & $<^{*}$ \\
\hline 3 & & & - & $<^{*}$ & & & - & $<^{*}$ \\
\hline 4 & & & & - & & & & - \\
\hline
\end{tabular}

Notes: ${ }^{* * *}$ denote 5 and $10 \%$ level of significance, respectively. $>$ the mean of the distribution in the row is grater than the mean of the distribution in the column; = the means are 
equal.

Table 2. Test (2) - (4) EOp 1 and EOp 2

\begin{tabular}{|c|c|c|c|c|c|c|c|c|c|c|c|c|c|c|c|c|}
\hline \multicolumn{9}{|c|}{ First Order Dominance } & \multicolumn{8}{|c|}{ Second Order Dominance } \\
\hline & \multicolumn{4}{|c|}{ North-Centre } & \multicolumn{4}{|c|}{ South } & \multicolumn{4}{|c|}{ North-Centre } & \multicolumn{4}{|c|}{ South } \\
\hline \multicolumn{9}{|c|}{ Graduation mark } & \multicolumn{8}{|c|}{ Graduation mark } \\
\hline & 1 & 2 & 3 & 4 & 1 & 2 & 3 & 4 & 1 & 2 & 3 & 4 & 1 & 2 & 3 & 4 \\
\hline 1 & - & $<^{*}$ & $<^{*}$ & $<$ & - & $<$ & $<^{*}$ & $<^{*}$ & - & $<^{* *}$ & $<^{*}$ & $<^{*}$ & - & $<^{*}$ & $<^{*}$ & $<^{*}$ \\
\hline 2 & & - & $<^{*}$ & $<$ & & - & $<^{*}$ & $<^{*}$ & & - & $<^{*}$ & $<^{*}$ & & - & $<^{*}$ & $<^{*}$ \\
\hline 3 & & & - & $<$ & & & - & $<^{*}$ & & & - & $<^{*}$ & & & - & $<^{*}$ \\
\hline 4 & & & & - & & & & - & & & & - & & & & - \\
\hline \multicolumn{9}{|c|}{ Income 3 years after graduation } & \multicolumn{8}{|c|}{ Income 3 years after graduation } \\
\hline 1 & - & $<^{*}$ & $<^{*}$ & $<$ & - & $\neq$ & $<^{*}$ & $<^{*}$ & - & $<^{*}$ & $<^{*}$ & $<^{*}$ & - & $\neq^{*}$ & $<^{*}$ & $<^{*}$ \\
\hline 2 & & - & $\neq^{*}$ & $\neq$ & & - & $<^{*}$ & $<^{*}$ & & - & $\neq^{*}$ & $\neq^{*}$ & & - & $<^{*}$ & $<^{*}$ \\
\hline 3 & & & - & $\neq$ & & & - & $<^{*}$ & & & - & $\neq^{*}$ & & & - & $<^{* *}$ \\
\hline 4 & & & & - & & & & - & & & & - & & & & - \\
\hline \multicolumn{9}{|c|}{ Income } & \multicolumn{8}{|c|}{ Income } \\
\hline 1 & - & $\neq^{*}$ & $<^{*}$ & $<$ & - & $\not$ & $\neq^{*}$ & $<^{* *}$ & - & $\neq^{*}$ & $<^{*}$ & $<^{*}$ & - & $\neq^{*}$ & $\neq^{*}$ & $<^{* *}$ \\
\hline 2 & & - & $\neq^{*}$ & $<$ & & - & $\neq^{*}$ & $<^{*}$ & & - & $\neq^{*}$ & $<^{*}$ & & - & $\neq^{*}$ & $<^{*}$ \\
\hline 3 & & & - & $<$ & & & - & $<^{*}$ & & & - & $<^{*}$ & & & - & $<^{*}$ \\
\hline 4 & & & & - & & & & - & & & & - & & & & - \\
\hline
\end{tabular}

Notes: $>$ the row dominates the column; $<$ the column dominates the row $=$ the curves are equal; $\neq$ the curves are different and cannot be ranked. See also notes to Table 1.

Table 3. Test (5) IOP 1

\begin{tabular}{|c|c|c|c|}
\hline \multicolumn{5}{|c|}{ Graduation mark } \\
\hline & North-Centre & & South \\
\hline 1 & & $<$ & \\
\hline $1+2$ & & $<$ & \\
\hline $1+2+3$ & & $>$ & \\
\hline $1+2+3+4$ & & $<$ & \\
\hline Income after 3 years from graduation \\
\hline 1 & \multicolumn{5}{|c|}{} & $>$ & \\
\hline $1+2$ & & $>$ & \\
\hline $1+2+3$ & & $>$ & \\
\hline $1+2+3+4$ & Income & $>$ & \\
\hline \multicolumn{5}{|c|}{} & $>$ & \\
\hline 1 & & $>$ & \\
\hline $1+2$ & & $>$ & \\
\hline $1+2+3$ & & $>$ & \\
\hline $1+2+3+4$ & &
\end{tabular}

Notes: See notes to Table 1. 


\begin{tabular}{|c|c|c|c|c|c|}
\hline \multicolumn{7}{|c|}{ Table 4. Test (6) IOP2 } \\
\hline \multicolumn{7}{|c|}{ Graduation mark } \\
\hline \multicolumn{7}{|c|}{1} & \multicolumn{5}{c|}{ North-Centre } \\
\hline South & 1 & $>^{*}$ & & & \\
\hline & $1+2$ & & $>^{*}$ & & \\
\hline \multicolumn{7}{|c|}{$1+2+3$} & & & $<^{*}$ & \\
\hline & $1+2+3+4$ & & & & $>^{*}$ \\
\hline Income after 3 years from graduation \\
\hline South & 1 & $<^{*}$ & & & \\
\hline \multicolumn{7}{|c|}{ Income } \\
\hline & $1+2$ & & $<^{*}$ & & \\
\hline & $1+2+3$ & & & $<^{*}$ & \\
\hline \multicolumn{7}{|c|}{$1+3+4$} & & & & $<^{*}$ \\
\hline & 1 & $\neq^{*}$ & & & \\
\hline \multicolumn{7}{|c|}{$1+2$} & & $<^{*}$ & & \\
\hline & $1+2+3$ & & & $<^{*}$ & \\
\hline
\end{tabular}

Notes: See notes to Tables 1 and 2 . 


\section{Appendices}

\subsection{Summary statistics}

Table 5. Summary statistics

\begin{tabular}{|c|c|c|c|c|}
\hline Types & \multicolumn{2}{|c|}{ North-Centre } & \multicolumn{2}{|l|}{ South } \\
\hline & $\begin{array}{l}\text { Mean }^{1} \\
\text { Std Err }\end{array}$ & $N^{3}$ & $\begin{array}{l}\text { Mean } \\
\text { Std Err }\end{array}$ & $N^{3}$ \\
\hline \multicolumn{5}{|c|}{ Graduation mark } \\
\hline 1 & $\begin{array}{c}83.24 \\
40.8\end{array}$ & 2090 & $\begin{array}{l}82.03 \\
42.12 \\
\end{array}$ & 1649 \\
\hline 2 & $\begin{array}{c}84.80 \\
39.6\end{array}$ & 4217 & $\begin{array}{l}85.87 \\
39.97\end{array}$ & 2845 \\
\hline 3 & $\begin{array}{l}88.53 \\
36.48 \\
\end{array}$ & 6723 & $\begin{array}{l}90.75 \\
36.07 \\
\end{array}$ & 4243 \\
\hline 4 & $\begin{array}{l}97.62 \\
25.95\end{array}$ & 4451 & $\begin{array}{l}99.39 \\
26.08\end{array}$ & 3630 \\
\hline Tot & $\begin{array}{c}89.31 \\
35.9\end{array}$ & 17481 & $\begin{array}{l}91.1 \\
35.9\end{array}$ & 12367 \\
\hline \multicolumn{5}{|c|}{ Income after 3 years from graduation ${ }^{4}$} \\
\hline 1 & 1097.6 & 1288 & $\begin{array}{l}866.3 \\
631.1\end{array}$ & 866 \\
\hline 2 & $\begin{array}{c}1119.9 \\
548.3\end{array}$ & 2610 & $\begin{array}{c}945.01 \\
635.2\end{array}$ & 1529 \\
\hline 3 & $\begin{array}{c}1126.2 \\
573.6\end{array}$ & 4246 & $\begin{array}{c}973.84 \\
612.2 \\
\end{array}$ & 2373 \\
\hline 4 & $\begin{array}{c}1133.9 \\
639.5\end{array}$ & 2534 & $\begin{array}{c}996.05 \\
663.5\end{array}$ & 1771 \\
\hline Tot & $\begin{array}{c}1123.1 \\
581.1\end{array}$ & 10678 & $\begin{array}{c}958.87 \\
635.4\end{array}$ & 6539 \\
\hline \multicolumn{5}{|c|}{ Income $^{5}$} \\
\hline 1 & $\begin{array}{c}27117.6 \\
25520.9\end{array}$ & 287 & $\begin{array}{c}22031.3 \\
14454.1\end{array}$ & 177 \\
\hline 2 & $\begin{array}{c}29374.1 \\
23496.6\end{array}$ & 189 & $\begin{array}{c}22132.1 \\
12809.4\end{array}$ & 100 \\
\hline 3 & $\begin{array}{c}31838.3 \\
31780.8\end{array}$ & 256 & $\begin{array}{c}22134.6 \\
15672.4 \\
\end{array}$ & 124 \\
\hline 4 & $\begin{array}{c}38239.1 \\
39384.2\end{array}$ & 261 & $\begin{array}{c}26571.7 \\
17524.4\end{array}$ & 162 \\
\hline Tot & $\begin{array}{c}31687.3 \\
31256.1\end{array}$ & 993 & $\begin{array}{c}23944.5 \\
15473.3\end{array}$ & 563 \\
\hline
\end{tabular}

Notes: ${ }^{1}$ Sample Mean; ${ }^{2}$ Sample Standard error; ${ }^{3}$ Sample number of observations; ${ }^{4}$ Monthly income; ${ }^{4}$ Annual income

\subsection{Proofs}

\section{Proof. of Theorem 2}

We first state and prove the following Lemma.

Lemma $1 \sum_{k=1}^{n} v_{k} w_{k} \geq 0$ for all sets of real numbers $\left\{v_{k}\right\}$ such that $v_{k} \geq$ $v_{k+1} \geq 0, \forall k \in\{1, \ldots, n\}$, if and only if $\sum_{i=1}^{k} w_{i} \geq 0, \forall k \in\{1, \ldots, n\}$.

\section{Proof. of Lemma 1}

Applying Abel's decomposition: $\sum_{k=1}^{n} v_{k} w_{k}=\sum_{k=1}^{n}\left(v_{k}-v_{k+1}\right) \sum_{i=1}^{k} w_{i}$. It is obvious that, if $\sum_{i=1}^{k} w_{i} \geq 0, \forall k \in\{1, \ldots, n\}$, then $\sum_{k=1}^{n} v_{k} w_{k} \geq 0$. As for the necessity part, suppose that $\sum_{k=1}^{n} v_{k} w_{k} \geq 0$ for all sets of numbers $\left\{v_{k}\right\}$ such 
that $v_{k} \geq v_{k+1} \geq 0$, but $\exists j \in\{1, \ldots, n\}$ such that $\sum_{i=1}^{j} w_{i}<0$. Consider what happens when $\left(v_{k}-v_{k+1}\right) \searrow 0, \forall k \neq j$. We obtain: $\sum_{k=1}^{n} v_{k} w_{k} \rightarrow\left(v_{j}-\right.$ $\left.v_{j+1}\right) \sum_{i=1}^{j} w_{i}<0$, which is the desired contradiction.

We can now prove the theorem, which states that $\Delta W=W(F)-W(G) \geq 0$, for all $W \in \mathbf{W}_{E O P 2}$, if and only if

$$
\sum_{i=1}^{k} q_{i}^{F} G_{i}(x) \geq \sum_{i=1}^{k} q_{i}^{G} F_{i}(x), \forall x \in[0, z], \forall k \in(1, \ldots, n) .
$$

By definition, $\Delta W \geq 0, \forall W \in \mathbf{W}_{E O P 2}$, if and only if

$$
\sum q_{i}^{F} \int_{0}^{z} U^{i}(x) f^{i}(x) d x-\sum q_{i}^{G} \int_{0}^{z} U^{i}(x) g^{i}(x) d x \geq 0
$$

for all the functions $U^{i}$ satisfying conditions C.1 and C.4. Using integration by parts, we obtain that $\Delta W \geq 0$ if and only if

$$
\begin{aligned}
\sum q_{F}^{i}\left[U^{i}(x) F^{i}(x)\right]_{0}^{z} & -\sum q_{i}^{F} \int_{0}^{z} \frac{d U^{i}}{d x} F^{i}(x) d x-\sum q_{i}^{G}\left[U^{i}(x) G^{i}(x)\right]_{0}^{z}+ \\
& +\sum q_{i}^{G} \int_{0}^{z} \frac{d U^{i}}{d x} G^{i}(x) d x \geq 0 .
\end{aligned}
$$

Now we know that $F^{i}(z)=G^{i}(z)=1$, hence the above expression reduces to:

$$
\sum\left[q_{i}^{F}-q_{i}^{G}\right] U^{i}(z)+\sum \int_{0}^{z} \frac{d U^{i}}{d x}\left[q_{i}^{G} G^{i}(x)-q_{i}^{F} F^{i}(x)\right] d x \geq 0 .
$$

Now, considering that, by condition (C.4) $U^{i}(z)=U^{j}(z)$, and that $\sum_{i=1}^{n} q_{i}^{F}=$ $\sum_{i=1}^{n} q_{i}^{G}=1$, we obtain that $\Delta W \geq 0$ if and only if

$$
\sum_{i=1}^{n} \int_{0}^{z} \frac{d U^{i}}{d x}\left[q_{i}^{G} G^{i}(x)-q_{i}^{F} F^{i}(x)\right] d x \geq 0
$$

or, equivalently,

$$
\int_{0}^{z} T(x) d x \geq 0
$$

where

$$
T(x)=\sum_{i=1}^{n} \frac{d U^{i}}{d x}\left[q_{i}^{G} G^{i}(x)-q_{i}^{F} F^{i}(x)\right]
$$

Now considering that, by conditions (C.1) and (C.3), $\frac{d U^{i}(x)}{d x}-\frac{d U^{i+1}(x)}{d x} \geq 0$, we can apply Lemma 1 . Hence we obtain that $T(x) \geq 0, \forall U$ satisfying C.1 and C.3, if and only if

$$
\sum_{i=1}^{k} q_{i}^{F} G_{i}(x) \geq \sum_{i=1}^{k} q_{i}^{G} F_{i}(x), \forall x \in[0, z], \forall k \in(1, \ldots, n)
$$


Clearly, if $T(x) \geq 0 \forall x$, then $\int_{0}^{z} T(x) d x \geq 0, \forall x$, which proves the sufficiency part of the theorem.

As for the necessity part, suppose, for a contradiction, that $\Delta W \geq 0, \forall W \in$ $\mathbf{W}_{E O P 2}$ and $\forall F, G \in \Psi$, but $\exists h \in\{1, \ldots, n\}$ and $\exists I \equiv[a, b] \subseteq[0, z]$ such that $\sum_{i=1}^{h}\left(q_{i}^{F} G_{i}(x)-q_{i}^{G} F_{i}(x)\right)<0, \forall x \in I$. Then, by Lemma $1, \exists$ a set of functions $\left\{U_{i}:[0, z] \rightarrow \Re_{+}, i \in\{1, \ldots, n\}\right\}$ such that $\sum_{i=1}^{n} \frac{d U^{i}}{d x}\left[q_{i}^{G} G^{i}(x)-q_{i}^{F} F^{i}(x)\right]<0$ $\forall x \in I$. Thus we have $\Delta W=\int_{0}^{1} T(x) d x$, where $T(x)<0 \forall x \in I$. Clearly, $\int_{a}^{b} T(x) d x<0$. Now we can select a function $T(x)$ (i.e., sets of functions $U_{i}$ and distributions $F_{i}(x)$ and $\left.G_{i}(x)\right)$ such that $T(x) \searrow 0 \forall x \in[0, z] \backslash I$. In this case we obtain that $\Delta W=\int_{0}^{1} T(x) d x \rightarrow \int_{a}^{b} T(x) d x<0$. A contradiction.

\subsection{Statistical tests}

The testing procedures used in the empirical application of this paper have been developed by Beach and Davidson (1983) and Davidson and Duclos (2000). We consider mainly equality tests and stochastic dominance tests of first and second order. In this Appendix, as a matter of notation, we represent the two order of stochastic dominance using the integral operator, $I_{j}(. ; F)$ to be the function that integrates the function $F$ to order $j$.

$$
\begin{aligned}
& I_{1}(x, F)=F(x) \\
& I_{2}(x, F)=\int_{0}^{x} F(t) d t=\int_{0}^{x} I_{1}(t ; F) d t .
\end{aligned}
$$

The general hypotheses for testing stochastic dominance of order $j$ of the distribution $F$ over $G$ can be written as follow:

$$
\begin{aligned}
& H_{0}^{j} \quad: \quad I_{j}(x, F) \leq I_{j}(x, G) \forall x \in[0, z] \\
& H_{1}^{j} \quad: \quad I_{j}(x, F)>I_{j}(x, G) \forall x \in[0, z] .
\end{aligned}
$$

The tests are based on comparisons of the (difference in the) distribution functions (and integrals thereof) at a fixed number of points, $k$ (in the paper we use 5 points in the outcome variable range). Defining those differences as a $(k \times 1)$ vector $\boldsymbol{\Delta}_{j}\left(x_{l}\right)=I_{j}\left(x_{l}, F\right)-I_{j}\left(x_{l}, G\right)$ we specify the equality and the stochastic dominance test accordingly.

Equality tests. The equality of distributions test is performed by a Wald test and apply a $\chi^{2}$ test. The hypothesis system is the following:

$$
\begin{array}{ll}
H_{0}: & \Delta_{j}\left(x_{l}\right)=0 \text { for all } l \in\{1, \ldots, k\} \\
H_{1} & : \quad \Delta_{j}\left(x_{l}\right) \neq 0 \text { for some } l \in\{1, \ldots, k\} .
\end{array}
$$

Defining $\hat{\boldsymbol{\Delta}}_{j}$ as the $(k \times 1)$ vector of estimates of $\Delta_{j}\left(x_{l}\right)$ and $\hat{\boldsymbol{\Sigma}}_{j}$ as the estimates of the variance covariance matrix of $\hat{\boldsymbol{\Delta}}_{j}$, it can be shown that under the null 
hypothesis, the $(k \times 1)$ vector $\hat{\boldsymbol{\Delta}}_{j}$ is asymptotically normal such that:

$$
\hat{\boldsymbol{\Delta}}_{j} \sim N\left(0, \hat{\boldsymbol{\Sigma}}_{j}\right)
$$

where $\hat{\boldsymbol{\Sigma}}_{j}=\frac{\boldsymbol{\Sigma}_{j F}}{N_{F}}+\frac{\boldsymbol{\Sigma}_{j G}}{N_{G}}$. Therefore, the statistic under the null hypothesis is

$$
\hat{W}_{j 1}=\hat{\boldsymbol{\Delta}}_{j}^{\prime} \hat{\boldsymbol{\Sigma}}_{j}^{-1} \hat{\boldsymbol{\Delta}}_{j} \sim \chi_{k}^{2} .
$$

See Beach and Davidson (1983) for details.

Stochastic dominance tests. In this case we follow the methods considered in Davidson and Duclos (2000) which are designed to test the following hypotheses

$$
\begin{array}{ll}
H_{0}^{j}: & \Delta_{j}\left(x_{l}\right) \leq 0 \text { for all } l \in\{1, \ldots, k\} \\
H_{1}^{j} & : \quad \Delta_{j}\left(x_{l}\right)>0 \text { for some } l \in\{1, \ldots, k\}
\end{array}
$$

then the Wald test can be obtained by

$$
\begin{aligned}
\hat{W}_{j 2} & =\min _{\Delta \in R_{+}^{k}}\left\{\left(\hat{\boldsymbol{\Delta}}_{j}-\boldsymbol{\Delta}_{j}\right)^{\prime} \hat{\boldsymbol{\Sigma}}_{j}^{-1}\left(\hat{\boldsymbol{\Delta}}_{j}-\boldsymbol{\Delta}_{j}\right)\right\} \\
& =\sum_{l=0}^{k} w(k, k-l, \boldsymbol{\Sigma}) \operatorname{Pr}\left(\chi_{j}^{2} \geq c\right)
\end{aligned}
$$

with the weights $w$ denoting the probability that $k-l$ elements of $\boldsymbol{\Delta}_{j}$ are strictly positive. As showed by Wolak (1989), the Wald statistic has an asymptotic distribution that is a mixture of chi-squared random variables. In particular, as noted in Barret and Donald (2003), we compute the solutions to a large number of quadratic programming problems in order to estimate the weights that appear in the chi-squared mixture limiting distribution and estimate the p-value of $\hat{W}_{j 2}$ using Monte Carlo simulation. ${ }^{16}$ See Wolak (1989), Davidson and Duclos (2000) and Barrett and Donald (2003) for details.

\section{References}

[1] Aaberge, R., Colombino U. and Romer, J.E. (2003) Optimal taxation according to equality of opportunity: a microeconometric simulation analysis. ICER Working Paper 5.

[2] Arneson, R. (1989) Equality of Opportunity for Welfare. Philosophical Studies, vol. 56, pp. 77-93.

\footnotetext{
${ }^{16}$ We determine the weights $w$ numerically. We draw 1000 multivariate standard normal vectors and pre-multiply it by the Cholesky decomposition of a consistent estimate of $\boldsymbol{\Sigma}$. Hence we compute the proportion of vectors with $l$ positive elements. This proportion is an estimate of the weight $w(k, l, \boldsymbol{\Sigma})$.
} 
[3] Arlegi, R. and J. Nieto (1999) Equality of opportunity: Cardinality-based criteria. In: de Swart H (ed) Logic, Game Theory and Social Choice. Tilburg University Press, Tilburg, pp. 458-481.

[4] Arrow, K., S. Bowles and Durlauf, S.N. (eds.) (2000) Meritocracy and economic inequality, Princeton University Press.

[5] Barry, B. (1991) Chance, choice and justice. In his Liberty and Justice: Essays in Political Theory, vol. 2. Oxford: Oxford University Press.

[6] Beach, C. M. and R. Davidson (1983) Distribution-free statistical inference with Lorenz curves and income shares. Review of Economic Studies, pp. 723-735.

[7] Becker, G.S. (1993). Human Capital: A Theoretical and Empirical Analysis, with Special Reference to Education. Chicago, University of Chicago Press. (First edition, 1964).

[8] Betts, J.R. and J.E. Roemer, (1999) Equalizing opportunities through educational finance reform. University of California, Davis, mimeo.

[9] Bourguignon, F, Ferreira F.H.G. and Menendez, M. (2003) Inequality of Outcomes and Inequality of Opportunities in Brazil. DELTA Working Papers 24 .

[10] Bossert, W., M. Fleurbaey and Van de gaer, D. (1999) Responsibility, talent, and compensation: A second-best analysis. Review of Economic Design, vol. 4, pp. 35-55.

[11] Checchi D. and V. Dardanoni (2002) Mobility Comparisons: Does using different measures matter? Research on Economic Inequality, vol. 9, pp. 113-145.

[12] Checchi, D., Fiorio C.V. and Leonardi, M. (2007) Intergenerational persistence in educational attainment in Italy. University of Milan, mimeo.

[13] Checchi, D. and L. Flabbi (2007) Intergenerational mobility and schooling decisions in Italy and Germany: the impact of secondary school track. IZA Working Paper 2879.

[14] Checchi, D. and V. Peragine (2005) Regional disparities and inequality of opportunity: the case of Italy. IZA Working Paper 1874.

[15] Cohen, G. A. (1989) On the currency of egalitarian justice. Ethics, vol. 99, pp. 906-944.

[16] Coniglio, N. and V. Peragine (2007) Giovani al Sud: tra immobilità sociale e mobilità territoriale in Coniglio N. and Ferri G. Primo Rapporto Banche e Mezzogiorno. Università degli Studi di Bari. 
[17] Dardanoni, V., Fields, G., Roemer, J. and Sanchez Puerta, M. (2005) How demanding should equality of opportunity be, and how much have we achieved?, in S. L. Morgan, D. Grusky and G. Fields (eds), Mobility and Inequality: Frontiers of Research in Sociology and Economics, Stanford University Press, Stanford.

[18] Davidson, R. and J.Y. Duclos (2000) Statistical inference for stochastic dominance and for the measurement of poverty and inequality. Econometrica, vol 68, pp. 1435-1464.

[19] De Villé, P. (2003) Equal opportunities in the educational system and the ethics of responsibility. Cahier de recherche en 'education et formation, 17.

[20] Dworkin R. (1981) What is equality? Part1: Equality of welfare. Part2: Equality of resources. Philosophy and Public Affairs vol. 10, pp. 185246;pp. 283-345.

[21] Goux, D. and E. Maurin (2003). On the evaluation of equality of opportunity for income: Axioms and evidence, CREST, mimeo.

[22] Herrero, C, (1997) Equitable opportunities: An extension. Economics Letters, vol. 55, pp. 91-95.

[23] Herrero, C., Iturbe-Ormaetxe I. and Nieto, J. (1998) Ranking opportunity profiles on the basis of the common opportunities. Mathematical Social Sciences, vol. 35, pp. 273-289.

[24] Kranich L. (1996) Equitable opportunities: an axiomatic approach. Journal of Economic Theory 71, 131-147.

[25] Kranich, L. (1997) Equitable opportunities in economic environments. Social Choice and Welfare, vol. 14, pp. 57-64.

[26] Kranich, L. (2003) Measuring opportunity inequality with monetary transfers. Discussion Paper No. 99-02, Department of Economics, State University of New York at Albany.

[27] Jenkins, S. and P.J. Lambert (1993) Ranking Income Distributions When Needs Differ. Review of Income and Wealth, vol. 39, pp. 337-56.

[28] Lefranc, A., N. Pistolesi and Trannoy, A. (2006a) Inequality of opportunities vs inequality of outcomes: Are Western Societies all alike? Working Papers 54, ECINEQ, Society for the Study of Economic Inequality.

[29] Lefranc, A., N. Pistolesi and Trannoy, A. (2006b) Equality of Opportunity: definitions and testable conditions with an application to France. Working Papers 53, ECINEQ, Society for the Study of Economic Inequality. 
[30] O'Neill, D., O. Sweetman and Van De Gaer, D. (1999) Equality of opportunity and kernel density estimation: An application to intergenerational mobility, Economics Department Working Papers 950999, National University of Ireland. Maynooth.

[31] Ok, E.A. (1997) On opportunity inequality measurement. Journal of Economic Theory, vol. 77 , pp. 300-329.

[32] Ok, E.A. and L. Kranich (1998) The measurement of opportunity inequality: A cardinality-based approach. Social Choice and Welfare, vol. 15, pp. 263-287.

[33] Peragine, V. (2002) Opportunity egalitarianism and income inequality. Mathematical Social Sciences, vol. 44, pp. 45-64.

[34] Peragine, V. (2004) Measuring and implementing equality of opportunity for income. Social Choice and Welfare, vol 22, pp. 187-210.

[35] Peragine, V. (2005) Ranking income distributions according to equality of opportunity. Journal of Economic Inequality, vol. 2, pp. 11-30.

[36] Roemer, J.E. (1993) A pragmatic theory of responsibility for the egalitarian planner. Philosophy and Public Affairs, vol. 22, 146-166.

[37] Roemer, J.E. (1998) Equality of opportunity, Cambridge, MA: Harvard University Press.

[38] Roemer, J., R. Aaberge, U. Colombino, J. Fritzell, S.P. Jenkins, A. Lefranc, I. Marx, M. Page, E. Pommer, J. Ruiz-Castillo, M.J. San Segundo, T. Tranaes, A. Trannoy, G. Wagner and I. Zubiri (2003) To what extent do fiscal regimes equalize opportunities for income acquisition among citizens?, Journal of Public Economics, vol. 87, pp. 539-565.

[39] Ruiz Castillo, J. (2003), The measurement of inequality of opportunities, in Bishop, J. and Y. Amiel (eds.), Research in Economic Inequality, 9: 1-34.

[40] Savaglio, E. and S. Vannucci (2007) Filtral preorders and opportunity inequality. Journal of Economic Theory, vol. 127, pages 474-492.

[41] Sen, A. (1970) Collective choice and social welfare, San Francisco: Holden Day.

[42] Sen A. (1980) Equality of what? In McMURRIN (ed.) The Tanner Lectures on Human Values. Vol 1. Salt Lake City: University of Uthh Press.

[43] Shorrocks, A. (1983) Ranking income distributions. Economica, vol. 50, pp.1-17.

[44] Van de gaer D. (1993) Equality of opportunity and investment in human capital. Ph.D. Dissertation, Catholic University of Louvain. 
[45] Villar, A. (2006) On the welfare evaluation of income and opportunity. Contributions to Theoretical Economics, Berkeley Electronic Press, vol. 5, pp 1129-1129.

[46] Waltenberg, F. (2006) Educational justice as equality of opportunity for achieving essential educational outcomes. Universite Catholique de Louvain, mimeo.

[47] Weymark, J.A. (2003) Generalized Gini Indices of Equality of Opportunity. Journal of Economic Inequality, vol.1, pp. 5-24.

[48] Wolak, F.A. (1989) Testing inequality constraints in linear econometric models. Journal of Econometrics, vol. 41, pp. 205-235. 